\title{
Nuevos paisajes urbanos en la frontera: las "paseras" paraguayas entre Posadas (Argentina) y Encarnación (Paraguay) y el plan de obras de Yacyretá (2009-2010)*
}

\author{
New urban landscapes at the border: the paseras between Posadas \\ (Argentina) and Encarnación (Paraguay) and Yacyretá work plan \\ (2009-2010) \\ María Dolores Linares ${ }^{\star *}$ \\ Consejo Nacional de Investigaciones Científicas y Técnicas (CONICET) \\ Instituto de Estudios Socio-Históricos (IESH) Universidad Nacional de La Pampa
}

Recibido: 25.11.2016 Aprobado: 03.05.2017

\begin{abstract}
Resumen
El objetivo del presente artículo es describir los cambios en el espacio urbano fronterizo de Posadas (Argentina)-Encarnación (Paraguay), como consecuencias de la ejecución de las obras del Plan de Terminación Yacyretá (etapa final de la Represa Hidroeléctrica Binacional Yacyretá) en los últimos diez años y analizar su impacto en la práctica fronteriza de "comercio hormiga" llevado a cabo por las mujeres paraguayas "paseras". Para ello se utilizaron entrevistas multisituadas al actor transfronterizo "pasera" entre los años 2009 y 2010, las cuales se procesaron mediante la técnica de "relatos de vida comparados". También se empleó documentación inédita de la Empresa Binacional Yacyretá como fuentes secundarias.
\end{abstract}

Palabras clave: frontera, prácticas sociales, paisaje urbano.

Este artículo es resultado de la investigación que se realizó para la tesis doctoral de la autora, defendida en el año 2013. El doctorado fue financiado con una Beca Doctoral Tipo I y Tipo II de CONICET (2008-2013).

** Licenciada en Relaciones Internacionales (Universidad Nacional de Rosario, Argentina), Máster en Ciencias Sociales por l'École des Hautes Études en Sciences Sociales (EHESS, Paris), Doctora en Geografía (EHESS) y en Ciencias Sociales (Universidad de Buenos Aires). Investigadora Asistente del CONICET (Argentina) y docente de la Facultad de Ciencias Humanas de la Universidad Nacional de La Pampa (Argentina). Correo electrónico: linares.dolores@gmail.com. 


\begin{abstract}
The objective of the present article is to describe the changes in the urban landscape at the border area of Posadas (Argentine)-Encarnación (Paraguay) in the last ten years: the Plan de Terminación Yacyretá (final stage of the Represa Hidroeléctrica Binacional Yacyretá) and analyze its impact on the cross-border dynamics of informal trade by the Paraguayan women called "paseras". We made multi-situated interviews to the trans-frontier actor called "pasera" between the years 2009 and 2010, which were processed by "compared life-stories" tecniques and we used unpublished documents of the Empresa Binacional Yacyretá as secondary sources.
\end{abstract}

Key words: border, social practices, urban landscape.

\title{
Introducción
}

Este artículo trata sobre las consecuencias sociales que implican las transformaciones en los espacios fronterizos, especialmente teniendo en cuenta las prácticas sociales de circulación. Nuestro caso deestudioabordalas prácticas de "comercio hormiga"' (Benedetti, 2011) llevadas a cabo por las paseras paraguayas en la frontera entre las ciudades de Posadas (Argentina) y Encarnación (Paraguay). Desde 1990, las ciudades de Posadas (de 323.739 habitantes, según el censo 2010) y Encarnación (de 119.336 habitantes, según las estimaciones preliminares del censo nacional del año 2012) están vinculadas físicamente por una gran obra de infraestructura: el puente internacional San Roque González de Santa Cruz. Esta construcción, sumado al preexistente servicio de lanchas para cruzar el río Paraná, formaba un fluido sistema de comunicación internacional. Esta primera obra pública favoreció la generación, renovación y visibilización de prácticas sociales con características propias de un espacio fronterizo, entre ellas el "comercio hormiga"

1 Llamamos comercio hormiga a la labor de pasar diversas mercaderías en escasas cantidades a través de la frontera, con el fin de ganar un rédito económico en su reventa. Existe una modalidad en el lenguaje coloquial de los funcionarios de Aduana que se refiere al ingreso de mercancía sin declarar en escasas cantidades para no pagar tributo: el contrabando hormiga, que se caracteriza por pequeñas transgresiones a los regímenes vigentes en esos pasos fronterizos según el Código Aduanero (República Argentina, Ley No 22.415-Código Aduanero, publicado en el Boletín Oficial el 2 de marzo de 1981). Nosotros preferimos utilizar el término comercio hormiga por dos razones: primero, porque en algunos casos este comercio no incurre en transgresiones y, aunque incurriera, la connotación negativa del término nos resulta que apela a una distinción entre legalidad/ilegalidad que no siempre es tan evidente en la frontera y, segundo, porque las paseras entrevistadas se definieron a ellas mismas, en varias ocasiones, como "hormiguitas", debido a las particularidades de su trabajo cotidiano. 
de las paseras paraguayas, enmarcado en una larga historia de intercambios comerciales y sociales tradicionales entre las ciudades de Posadas y Encarnación (Linares, 2010; Schiavoni, 1993). Las "paseras" son mujeres cuyo trabajo consiste en "pasar" a través de la frontera argentino-paraguaya pequeñas cantidades de mercaderías para su venta, reventa o entrega, desde Encarnación a Posadas o viceversa ${ }^{2}$. Sin embargo, desde el año 2006, otra obra pública de gran envergadura comenzó a modificar este espacio de contacto entre las dos ciudades y las prácticas sociales desarrolladas a su alrededor: el Plan de Terminación Yacyretá (PTY), etapa final del proyecto de la Represa Hidroeléctrica Binacional Yacyretá, de la Empresa Binacional Yacyretá.

El PTY es un plan de obra pública que tiene como objetivo la realización de diversas reformas y acciones tanto del lado paraguayo como argentino para culminar el proyecto de la Central Hidroeléctrica de Yacyretá. La central requería, para funcionar en forma plena y eficientemente, una cota de embalse de ochenta y tres metros sobre el nivel del mar (msnm), por lo cual la prioridad del PTY fue finalizar las obras necesarias para poder elevar la cota a ese nivel en el eje Encarnación-Posadas. Los objetivos del plan fueron: 1) liberar las áreas que serían inundadas y aquellas necesarias para la construcción de las defensas costeras y obras anexas; 2 ) realizar obras y acciones necesarias para garantizar la calidad de vida ambiental; 3) reponer obras de infraestructura que serán afectadas, y 4) recomponer la trama urbana de Encarnación y Posadas.

Las obras de infraestructura del PTY, sobre todo las tendientes a alcanzar los objetivos 1, 3 y 4, generaron grandes transformaciones en las ciudades de Posadas y Encarnación. A partir del año 2009, la cota del río Paraná subió hasta sumergir amplios terrenos en ambas ciudades y, junto con ellos, lugares emblemáticos para la actividad de comercio informal llevado a cabo por las paseras paraguayas como los puertos en ambos márgenes y la "zona baja"3 comercial de Encarnación. Creemos que el proceso de cambio en el paisaje urbano de las ciudades mediante estas obras puede ser observado desde — por lo menos - dos escalas de análisis diferentes: por un lado, desde un marco supranacional y de infraestructura energética y, por el otro, desde una escala microsocial, que focaliza la mirada en las trayectorias de circulación fronterizas individuales y las estrategias laborales en contextos de cambio. El objetivo del presente artículo es describir los

2 Cabe destacar que en este espacio coexisten además otros "actores del comercio fronterizo", dado que la inauguración del puente internacional facilitó el movimiento de otros factores afines a la actividad que fuimos descubriendo a partir de la observación participante y de las entrevistas realizadas, estos son: taxistas, mototaxistas, estudiantes "paquitos", paseros y puesteros de los mercados "paraguayos", descritos en trabajos anteriores (Linares, 2013).

3 El casco histórico de Encarnación, devenido en centro comercial de la ciudad, es conocido comúnmente como "zona baja" por la gente del lugar. 
cambios en el espacio urbano fronterizo de Posadas (Argentina)-Encarnación (Paraguay) como consecuencia de la ejecución de las obras del Plan de Terminación Yacyretá (en adelante PTY) en los últimos diez años, y analizar su impacto en la práctica fronteriza de "comercio hormiga" de las mujeres paraguayas "paseras". Metodológicamente, para lograr nuestro objetivo utilizamos, como fuentes secundarias, publicaciones y planos inéditos de la Empresa Binacional Yacyretá. En particular, recabamos información sobre las obras realizadas en el margen izquierdo del río Paraná que corresponden al Proyecto $\mathrm{N}^{\circ} 3$ y 4 del PTY de la Empresa Binacional Yacyretá y su actualización en el Resumen Ejecutivo del año 2010. Las fuentes primarias utilizadas fueron entrevistas multisituadas realizadas al actor transfronterizo "pasera" en dos períodos diferenciados: en abril-mayo del año 2009 y en julio-agosto de 2010. El artículo está acompañado de un cuerpo de fotografías tomadas durante el trabajo de campo que marcan los cambios espacio-temporales en el área estudiada. Esta área no responde a la totalidad de espacios urbanos transformados por las obras del PTY, sino que está determinada por el "espacio vivido"4 (Di Meo, 1998) de las paseras paraguayas entre las ciudades de Posadas y Encarnación que se ha visto alterado por la ejecución de las distintas etapas del PTY. Específicamente, en el margen izquierdo del río, nuestra área de estudio abarca parte de la zona costera de la ciudad de Posadas, desde la cabecera argentina del Puente Internacional hasta la intersección de la nueva Avenida Costanera con la Avenida Roque Pérez, el área del Mercado Modelo La Placita y el barrio Villa Sarita, ubicado al norte del casco céntrico y delimitado por las avenidas Roca, Roque Pérez y la Avenida Costanera de Posadas. En el lado paraguayo margen derecho del río Paraná- se recorrió el viejo barrio comercial antes y después de su anegación por la subida de la cota del río Paraná y el nuevo barrio comercial, ubicado a pocos metros del Puente Internacional San Roque González de Santa Cruz.

Este trabajo se ordena a partir de cuatro ejes. En primer lugar, se aclaran las líneas conceptuales que estructuran el análisis de nuestro caso: frontera/espacio fronterizo, territorialización, prácticas de circulación y paisaje urbano. En segundo lugar, se describe la actividad cotidiana y tradicional de las paseras paraguayas entre las ciudades de Posadas y Encarnación. En un tercer momento se detallan las obras del PTY que han afectado el espacio vivido de estas mujeres paraguayas en su circulación fronteriza. Por último, se retoma la palabra de este actor para observar las consecuencias de estos cambios territoriales en la representación espacial de su actividad laboral.

4 Di Meo llama espacio vivido al conjunto de espacios y relaciones que, con un mínimo de continuidad y regularidad, hacen a la vida cotidiana de los habitantes del área. El espacio vivido está compuesto así por todos los lugares frecuentados en el recorrido fronterizo, las interrelaciones sociales de las cuales se nutre y los valores que son percibidos y proyectados sobre este espacio que remiten a la experiencia y a los saberes que acumulan los hombres (Di Meo, 1998, p. 31). 


\section{La frontera como construcción social: territorios, discontinuidades y prácticas sociales}

En este trabajo abordamos la frontera desde las perspectivas de la geografía del poder y de la geografía humana, que renovaron su interés en este tema entre los años 1970 y 1990, considerando este espacio ya no "como un contenedor de procesos sociales", sino como una construcción social en sí mismo (Arriaga Rodríguez, 2012, p. 84). Mientras el límite internacional es entendido política y jurídicamente como una línea que separa dos jurisdicciones y soberanías estatales, resultado de los instrumentos jurídicos de los Estados (tratados, convenciones, acuerdos, laudos) y marcado a partir de hitos (Pastor Ridruejo, 1992; Díez de Velasco, 1975), la frontera es un concepto más complejo, que se ha ido modificando al incorporar nuevos elementos a lo largo del tiempo (Ferrari, 2014).

La geografía política concibe a la frontera o al espacio fronterizo como el conjunto que incluye al límite internacional del Estado y a la franja de territorio adyacente a ambos lados (George, 1974). Para la geografía humana francesa, la noción de frontera como construcción social está íntimamente ligada a la noción de territorio, en tanto es entendida como un elemento político que marca y delimita un espacio en el que se ejerce algún tipo de control (Haesbaert, 2012). La territorialización es una práctica fundamental según la geografía del poder de Raffestin (1980, p. 249) que indica el accionar humano sobre el espacio, relacionándose así con la temporalidad de la vida social, con el tiempo de largo plazo y con el poder. Dentro de esta dimensión social y política del territorio encontramos la formación estatal, sus límites territoriales y la frontera, atravesados por la temporalidad.

En palabras de Foucher (1991, p. 38), las fronteras son "estructuras espaciales elementales que tienen por función la discontinuidad geopolítica” y la demarcación del espacio terrestre en unidades jurídicas y soberanas diferenciadas. Esta concepción de frontera nos lleva a pensarlas, siguiendo a Kralich, Benedetti y Salizzi (2012), como un espacio franja (a ambos lados del límite) o conjunto de lugares que organizan los territorios nacionales y que, como dispositivos, provocan discontinuidades espaciales. Una vez creadas, los efectos de las fronteras no operan solamente en el orden político o jurídico (sistemas de inclusión/exclusión), sino también en el ámbito social, especialmente en la construcción/ afirmación/reproducción de prácticas, identificaciones identitarias, representaciones sociales, etc. Encontramos asimismo prácticas sociales de circulación fronteriza que en algunos casos funcionan como continuidades que atraviesan o desafían la discontinuidad geográfica de la frontera, proponiendo otro tipo de territorialización que es producto de las disputas sociales por el espacio. Introducimos el término "territorialización en 
los intersticios", como veremos más adelante, para dar cuenta de estos tipos de creación de territorios que se desarrollan entre dos territorios nacionales, en los espacios en que los Estados disminuyen su control. Las prácticas sociales de circulación fronterizas son aquello que sucede en el "paso" o el cruce y en el espacio fronterizo, y que implican no solo a personas y lugares precisos sino también a medios de transporte, objetos, mercaderías, dinero y tipos de cambio, normas, funcionarios del Estado y tiempos. Las prácticas sociales de circulación alimentan, poco a poco, la generación y reproducción de vínculos de toda índole y nos acercan al carácter dinámico de las estrategias de construcción territoriales observadas en los espacios fronterizos (Cortés y Faret, 2009; Amilhat-Szary y Fourny, 2006) o transfronterizos. Como indicamos en trabajos anteriores (Linares, 2013), los espacios transfronterizos son lugares donde el tránsito prevalece sobre lo estático, donde la frontera es más permeable, donde el cruce, el paso, es parte cotidiana de la vida. Están compuestos por ciudades, zonas rurales y semirrurales, en donde existe una frontera internacional pero que, dada la vinculación tanto física como social, institucional, política y las prácticas sociales desarrolladas en la frontera, tienen una vida en común más allá de las decisiones del poder central de cada Estado involucrado. Dentro de estas prácticas, el "comercio hormiga" consiste en el cruce del límite, por lo menos una vez al día, de pequeñas cantidades de diversas mercancías con el fin comercial de venta o entrega. En general, es llevado a cabo por paseros que trabajan para terceros (comerciantes o particulares) a cambio de una muy baja remuneración. En este trabajo intentaremos acercarnos a la percepción o representación de las paseras paraguayas sobre el espacio en donde desarrollan su trabajo y su vida cotidiana.

Teniendo en cuenta estas percepciones, cuando nos referimos al paisaje urbano ponemos el acento no solo en la configuración espacial, material y "real" de la ciudad - que remite a la totalidad-, sino también a su representación, acercándonos así a la experiencia subjetiva del paisaje para las personas que lo habitan (Souto, 2011). La subjetividad del paisaje urbano se alimenta no solo de los espacios vividos, sino de los imaginarios o representaciones del mismo. Entendemos al paisaje como el conjunto de objetos que podemos percibir e identificar por medio de nuestros sentidos de esa configuración espacial, es decir, un sistema parcial y subjetivo (Santos, 1996). Aquí la perspectiva de Milton Santos sobre el paisaje nos es de utilidad a la hora de comprender que sus mutaciones pueden ser tanto estructurales como funcionales. En general, en la "fotografía" que implica un paisaje ("la materialización de un instante de la sociedad", en palabras de Santos 1996, p. 69), podríamos observar una relación entre la "estructura socio-espacial y la estructura socio-económica y política”. Muchas veces las formas envejecen en relación con las prácticas sociales y las nuevas funciones crean nuevas estructuras materiales. En este trabajo, veremos cómo aquello que se modifica, y en algunos casos muy rápidamente, 
son las estructuras espaciales, las formas, los caminos, los barrios, mientras se obliga a las prácticas sociales a adaptarse o a dejar de existir como tales.

\section{El oficio de cruzar: paseras paraguayas entre Posadas y Encarnación}

La práctica de "comercio hormiga" que realizan las paseras constituye una actividad observable en numerosos espacios fronterizos latinoamericanos, como lo demuestra el ejemplo de los sacoleiros y sacoleiras entre Brasil, Argentina y Paraguay (Corvalán y Elías, 1999), los bagayeros (frontera con Brasil así como con Bolivia) o los paseros, o ayucos (frontera con Bolivia), entre otros. En general, las paseras paraguayas entre Posadas y Encarnación provienen de Encarnación y sus alrededores. Se despiertan muy temprano y preparan las mercaderías que "pasarán" hacia Posadas. Ingresan y salen de la Argentina cuantas veces deseen gracias a la modalidad del Tránsito Vecinal Fronterizo, que es una categoría migratoria de ingreso y egreso para los habitantes fronterizos que buscan permanecer por breves lapsos en el territorio de los países vecinos (no más de setenta y dos horas) y en el ámbito propio de la frontera (no más de $50 \mathrm{~km}$ a la redonda). Si bien el "comercio hormiga" no implica necesariamente la realización de alguna actividad ilegal, generalmente incurren en pequeñas transgresiones a los Regímenes de Equipaje (franquicia de 150 dólares una vez por mes), Pacotilla, de Tráfico Vecinal Fronterizo (franquicia de 50 dólares una vez por mes para residentes de espacios fronterizos por el paso de productos de uso personal, del hogar y familiar) y Franquicias Diplomáticas, según los artículos 488/505 y 977/982 del Código Aduanero de la República Argentina (Ley $\mathrm{N}^{\circ}$ 22.415-Código Aduanero, publicado en el Boletín Oficial el 2 de marzo de 1981). La imposibilidad de ajustar esta práctica al Régimen aduanero del Tráfico Vecinal Fronterizo ${ }^{5}$ (Resolución General 262/98 AFIP Aduanas y complementarios) radica en tres razones: por un lado, porque las mercancías que ingresan al país no son originarias del Paraguay, es decir, han sido importadas previamente, generalmente desde Iquique, Chile (artículos de cosmética procedentes de China, termos de Alemania); por otro, porque ingresan al país mercancías prohibidas según el código aduanero, como

\footnotetext{
El Régimen del Tráfico Vecinal Fronterizo permite el intercambio de mercancías destinadas al uso o consumo doméstico entre las poblaciones fronterizas, libre de formalidades y del pago de impuestos aduaneros. Sus beneficiaros solo pueden ser pobladores de los países limítrofes residentes en zonas inmediatas a la frontera y están autorizados a trasladar fuera del territorio nacional, mercadería adquirida para uso personal (artículos de vestir y aseo, y demás bienes que revistan carácter personal), del hogar y consumo propio familiar. Los bienes no deben estar destinados a su comercialización y deben tener procedencia del país de origen. Para este tipo de bienes existe una franquicia de cincuenta (50) dólares estadounidenses (U\$S) que se utiliza solo una vez por mes.
} 
cigarrillos o bebidas alcohólicas importadas; y, finalmente, porque la ley establece un cupo de 150 dólares estadounidenses por mes en una sola vez de artículos de consumo no durables, mientras que las paseras cruzan la frontera todos los días y varias veces por día. Estas infracciones son las que causan momentos cotidianos de tensión en las diferentes instancias de control fronterizo llevadas a cabo por los organismos nacionales especializados como la Aduana Argentina o el Servicio Nacional de Sanidad y Calidad Agroalimentaria (en adelante SENASA), encargados de revisar los bolsos de las paseras. Pese a la dureza de los controles fronterizos, las paseras siguen realizando los cruces por la subsistencia ${ }^{6}$ y su circulación nos propone un viaje ida y vuelta a través de la frontera, un ir y venir incesante que, si bien se justifica con fines comerciales, nos hablarán también de relaciones familiares, de tradiciones e historias.

Aunque la presencia de las paseras en la ciudad de Posadas se ha hecho más evidente desde la inauguración del Puente Internacional en 1990, su actividad entre las dos ciudades se remonta por lo menos hasta apenas delimitada la frontera política entre Paraguay y Argentina. Unos años después del "Tratado de Límites entre la República Argentina y la República del Paraguay de 1876"7 (luego de la Guerra de la Triple Alianza de 1865), los relatos de los geógrafos y agrimensores enviados a fines del siglo XIX (De Bourgoing, 1984; Peyret, 1881) daban cuenta de la presencia de las paseras paraguayas entre Posadas y Encarnación. Durante más de un siglo llevaron a cabo su trabajo cruzando el río mediante botes, lanchas y embarcaciones precarias. La inauguración del puente en 1990 promovió el crecimiento de la actividad pero también rearticuló los controles fronterizos, generando a su vez reacomodamientos y nuevas estrategias en la práctica de las paseras. La manera de circular en el espacio fronterizo se fue especializando según las mercancías y los contactos laborales de las paseras con comerciantes a ambos lados del límite internacional. En la Figura 1 se sistematiza la información recabada en cuanto a la circulación de las paseras paraguayas en Posadas, teniendo en cuenta dos circuitos: el del ómnibus internacional y el de la lancha vía los puertos fluviales.

6 Es remarcable que una de las estrategias para sortear los obstáculos de los controles en "el cruce" consiste en la práctica ilegal del soborno - comúnmente llamada "coima" - pedido por el funcionario de control. En esos casos, la "dureza de los controles" no reside solamente en la letra de la norma, sino en su interpretación y uso discrecional - e ilegal- por parte de los encargados de ejercer el control en la frontera.

7 El Art. I de dicho Tratado establece: "La República del Paraguay se divide por la parte del Este y Sud de la República Argentina por la mitad de la corriente del canal principal del Río Paraná, desde su confluencia con el Río Paraguay, hasta encontrar por su margen izquierdo los límites del Imperio del Brasil (...)”. Tratado de Límites entre la República del Paraguay y la Argentina, del 03/02/1876, firmado por el Ministro de Relaciones Exteriores de la República Argentina, doctor don Bernardo de Irigoyen, y el Enviado Extraordinario y Ministro Plenipotenciario en Misión Especial, don Facundo Machain, aprobado por el Congreso Nacional por Ley № 770 del 7 de julio de 1876 
Figura 1: Área céntrica de Posadas y barrio Villa Sarita. Circuito de paseras paraguayas

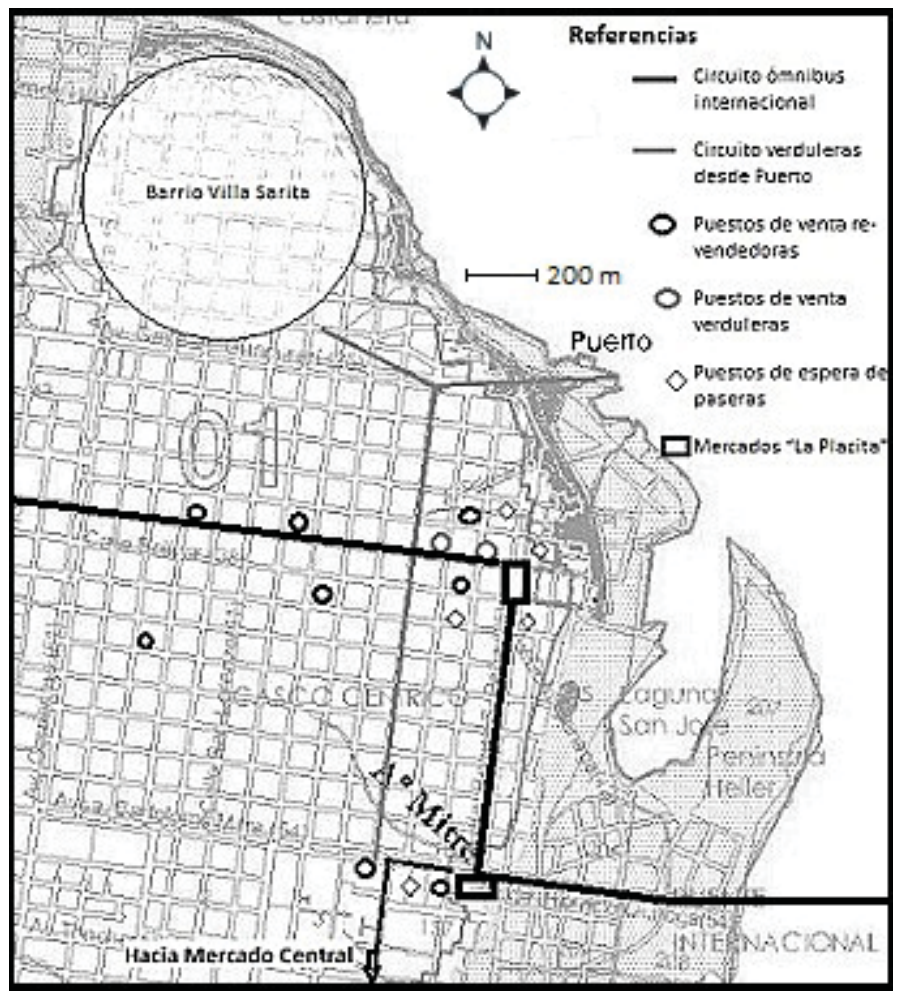

Fuente: elaboración propia sobre mapa base "Plano Áreas Posadas", gentileza de la Secretaría de Planificación Estratégica y Territorial, Municipalidad de Posadas, abril, 2009.

A partir de nuestro trabajo de campo de los años 2007 y 2009, hemos comprobado que, aunque se les llame generalmente paseras, no todas las mujeres paraguayas que trabajan en las calles de Posadas en alguna forma de comercio ambulante son paseras. Para ellas existe una diferenciación, que tiene que ver con la finalidad del "cruce" de mercancías que realizan y las estrategias que despliegan para lograr su objetivo: un cruce exitoso. Aunque conocemos sobre la existencia de otros tipos de paseras $^{8}$, a través de nuestro trabajo de campo pudimos caracterizar tres tipos (Linares, 2015):

8 A partir de la observación y de las entrevistas supimos sobre otros tipos de figuras del comercio fronterizo, como la de los taxistas, paquitos, mototaxistas, paseros, etc. También, las paseras entrevistadas nos contaban que 
1. Las "paseras" propiamente dichas: son las encargadas de "pasar" la mercadería como intermediarias entre comerciantes de Encarnación y de Posadas. Estas mujeres aseguran traer solamente mercaderías "permitidas": artículos textiles (manteles, toallas, sábanas, acolchados, repasadores, ropa en general), termos, paraguas, zapatillas de segundas marcas, maquillaje, medicamentos caseros (jarabes de miel y propóleos) y artículos para el cabello (hebillas, peines, etc.). Su jornada laboral comienza en un negocio en Encarnación donde hay mercadería para ella, que "la señora del mercado" de Posadas ya ha seleccionado y "arreglado" - pagado - con el dueño del negocio encarnaceno. Este tipo de paseras cruzan la frontera por vía terrestre, generalmente por el puente internacional, cargadas con poca mercadería (uno o dos bolsos). María relataba: "Yo paso cosas, nada más. Nosotras somos las hormiguitas. No traemos nada para vender, le traemos a la dueña y ella nos paga el paso nomás" (María, 27/04/09). Explicaban que en el puente las conocían y que en general las dejaban pasar. Marcia explicaba: "Si hay alguien medio malo sí, ahí esperamos todos, nos vamos avisando. Y si viene alguien bueno sí" (Marcia, 04/05/09). El ómnibus "Internacional" tiene parada en los llamados mercados paraguayos: el "Mercado La Placita del Puente", apenas a unos doscientos metros de la cabecera argentina del puente internacional, y el "Mercado Modelo La Placita", ubicado en el centro de la ciudad, a cuatrocientos metros del Puerto de Posadas (inundado desde el año 2010). A ambos se los denomina comúnmente "La Placita" (el Mercado Modelo como "La Placita" original y el cercano al puente como "La Placita del Puente"), porque es el nombre que remite a los orígenes de los mercados paraguayos de fines del siglo XIX, cuando las paseras provenientes de Encarnación llegaban al puerto de Posadas e improvisaban un mercado en el espacio verde central de la Avenida Roque Sáenz Peña (la "placita"), en donde ofrecían sus productos: frutas y verduras, yuyos medicinales, carnes de vaca o pollo, telas, harinas, legumbres, chipá o sopa paraguaya?.

Algunas paseras descienden a los mercados para hacer la entrega. Se quedan en una esquina y solo esperan, mientras se reparten la mercadería, que el "puestero" del mercado llegue a buscar lo que le pertenece. Algunas van con sus hijas o sus sobrinas,

"otras" paseras y los paseros se aventuraban en el "pase" de artículos electrónicos de pequeño y mediano porte, generalmente acordado el precio del "pase" previamente entre el comprador y el comerciante. Este tipo de paseras serían también intermediarias, pero su riesgo sería mayor por los montos de las mercaderías que trasladan.

$9 \quad$ Luego de desalojada "la placita" originaria, en 1934, la Municipalidad de Posadas hizo construir la Feria del Norte, ubicada en la Avenida Roque Pérez, pero en 1955, y por órdenes del interventor de la comuna, Cayetano Castelli, se clausuró. En 1961 se inauguró el Mercado Modelo que aún funciona en el centro de la ciudad. Se trata de una construcción arquitectónica desarrollista (Borio, 2009) de $3.500 \mathrm{~m}^{2}$ que tiene 296 puestos de ventas. Contaba con dos patios de luz y un bar-restaurante, que funcionaron hasta mediados de la década del 80 y luego fueron ocupados por más locales de venta. 
para ir enseñando el oficio y nos cuentan cómo ellas fueron iniciadas por su madre o una pariente cuando eran adolescentes. Todas regresan a Encarnación una vez que han entregado las mercaderías a sus dueños y cobran su parte de las ganancias. En general es solo un trabajo de ida. Sus estrategias principales consisten en "preparar el cruce", para lo cual el "armado de bolsos" de manera colectiva y solidaria entre ellas es fundamental. Dado que ninguna pasera podría cruzar la Aduana argentina con un bolso con diez termos, o con un bolso con diez pares de zapatillas - no podrían argumentar que es para "para uso personal", como lo permite la ley aduanera y las resoluciones del Tránsito Vecinal Fronterizo-, deben, entre varias, organizarse en una plaza de Encarnación o en la calle, para que cada una tome un termo, un paraguas, un par de zapatillas y puedan armar bolsos variados que les permitan alegar en la aduana que esa mercadería no es para la venta.

2. Las vendedoras o "revendedoras": son mujeres paraguayas que improvisan puestos de venta en la calle, en el centro o en las inmediaciones del Mercado Modelo "La Placita" de Posadas. La mayoría de ellas "pasa” mercadería "permitida” desde Encarnación. Traen pequeños bolsos con poca mercadería, en general artículos de cosmética, textiles, accesorios, pilas, a veces esconden un cartón de cigarrillos para aumentar su margen de ganancia. Estas mujeres no encuentran muchos problemas al cruzar la frontera, ya que lo hacen con poca mercadería, argumentando que es para "uso personal", aunque su trabajo en la calle es perseguido por los inspectores del municipio de Posadas. Por esta razón, las estrategias de estas mujeres tienen más que ver más con el propio trabajo en la ciudad que con el cruce, que realizan por el Puente Internacional en ómnibus. Algunas consiguen que alguien les "cuide" su stock en una casa en Posadas y ellas solo traen las mercancías que "reponen" de la venta del día anterior, como es el caso de Julia. La estrategia de Amanda, por otro lado, es "pasar poquito" y armar su puestito de hierbas medicinales y remedios caseros en las calles del centro, cada día en un lugar distinto. Otras se cuidan de ir a Posadas en horarios "seguros", es decir, cuando los inspectores de la municipalidad ya han terminado su jornada laboral. Se jactan de no trabajar para nadie, de ser independientes, de diferenciarse del primer tipo de paseras. Su ganancia reside de "hacer la diferencia" entre la compra a precio de mayorista y la reventa a precio minorista.

3. Las paseras verduleras: estas mujeres pertenecen a un sector de la actividad económica que solo comprende frutas y verduras. En algunos casos, el trabajo no implica necesariamente "pasar" mercadería a través de la frontera, aunque en general traen variada mercadería desde Encarnación: se aventuran con unas bolsitas de maíz o porotos, harina de mandioca, maní o unos pequeños ananás, siempre por medio 
de la lancha, porque en ese puesto no existe control fitosanitario y bromatológico (SENASA). Aquellas que cruzan sin pasar mercadería optan por el puente, porque es más rápido. Laureana dice que "en el colectivo [por el puente] nada ni un poroto no pasamos. Allá en la lancha pasamos bien”. Como veremos más adelante, el servicio de lanchas fue interrumpido el año 2009 y restituido recién en 2013, entorpeciendo el trabajo de las paseras verduleras. Una vez llegadas a Posadas, estas mujeres, tengan mercadería traída de Encarnación o no, recorren la ciudad de Posadas por medio del transporte público hasta el Mercado Central de Frutas y Verduras de la ciudad, a unos seis kilómetros del centro por la ruta 12. Allí se abastecen de aquello que van a vender en la ciudad: tomates, lechugas, naranjas, manzanas. $\mathrm{Y}$ a eso le agregan, generalmente, las bolsas de maní o porotos propios. Tienen dos maneras de trabajar: unas arman un puesto en las inmediaciones del "Mercado Modelo La Placita", donde todos las conocen y tienen sus clientes fijos entre los vecinos, y otras venden "casa por casa", dirigiéndose a diversos barrios de la ciudad en grupos de a cuatro o cinco mujeres, en general parientas o vecinas. En el Barrio Villa Sarita, por ejemplo, María Paula, Charo y Mara pasan todos los días, por la mañana, con sus canastas de frutas y verduras. Todas son de Cuatro Potreros, una zona rural al oeste de Encarnación. Todas tienen maridos que trabajan en las chacras, donde producen aquello que venderán. Se despiertan a las cuatro de la mañana, arman sus bolsitas de maíz y mandioca, y salen juntas a tomar un colectivo que las lleva hasta el puerto de Encarnación. Cruzan por medio de la lancha a las siete de la mañana y llegan a Posadas para dirigirse directamente al Mercado Central y luego al Barrio de Villa Sarita. María Paula dice: "Voy casa por casa. Este es el barrio que nosotros caminamos, siempre en Villa Sarita, siempre. Todos los días. (...) Y trabajo hasta que vendemos todo. Puede ser a las dos, las tres (de la tarde)...". Hay un trabajo individual que se hace en la venta casa por casa, pero se vive de manera grupal ("trabajo hasta que vendemos todo"). Y en Villa Sarita todos los vecinos las conocen. Al volver a Paraguay, aprovechan para llevar algún kilo de harina o litro de aceite.

Estas estrategias descritas se han ido acomodando a las modificaciones territoriales producidas por la inauguración del puente internacional - como punto de inflexión-y a la consiguiente sofisticación de los dispositivos de control fronterizo desarrollados en los últimos veinte años. En su circulación por dos territorios nacionales encontramos que han tenido posibilidades de "territorialización en los intersticios" - en los lugares menos controlados-, creando nuevos espacios bajo su dominio en donde descansar, almorzar, trabajar y conversar. Según la Real Academia Española, un intersticio es una "hendidura o espacio, por lo común pequeño, que media entre dos cuerpos o entre dos partes de un mismo cuerpo". Proponemos el término "territorialización en los intersticios" para dar cuenta de esos lugares construidos en los pequeños espacios que dejan las territorialidades 
estatales (en este caso, de dos estado nacionales) y que, como la hiedra entre las piedras, dibujan un camino a veces complejo pero donde es posible la subsistencia. Estos lugares "propios", productos de la territorialización del "comercio hormiga" de las paseras, se vieron comprometidos a partir del año 2009, cuando se comenzaron a observar y vivenciar los cambios en el paisaje urbano entre Posadas y Encarnación como consecuencia de las obras de infraestructura del PTY.

\section{Nuevo paisaje del espacio fronterizo: el Plan de Terminación de Yacyretá}

El Plan de Terminación de Yacyretá se enmarca en las obras tendientes a finalizar el gran proyecto de la Represa Hidroeléctrica Yacyretá de carácter binacional, presente en la agenda argentina y paraguaya desde 1958, cuando se firmó un convenio entre estos dos países para analizar la posible obtención de energía de los Saltos de Apipé. El 3 de diciembre de 1973 se firmó el Tratado de Yacyretá, el cual preveía la formación de la Entidad Binacional Yacyretá (EBY), que en septiembre de 1974 estableció sus oficinas centrales en Asunción y Buenos Aires. Con respecto a su ubicación geográfica, la represa de Yacyretá está emplazada sobre el río Paraná, entre Argentina y Paraguay. En los márgenes se encuentran las ciudades de Ituzaingó, provincia de Corrientes (Argentina) y Ayolas, departamento de Misiones (Paraguay), respectivamente, a unos cien kilómetros de las ciudades de Posadas y Encarnación aproximadamente. Este proyecto geopolítico preveía, originariamente, la inundación de forma permanente de ochenta mil hectáreas en Paraguay y treinta mil hectáreas en Argentina (Simoe, 2001). Finalmente, el lago artificial creado por la represa tuvo una superficie de $16.000 \mathrm{~km}^{2}(160.000 \mathrm{ha})$.

En junio 1994 comenzó el proceso de llenado del embalse de la represa hasta la cota 76 msnm y se inauguró la Central Hidroeléctrica de Yacyretá, con la puesta en funcionamiento de la Unidad de Generación $\mathrm{N}^{\circ} 1$. El llenado fue realizado gradualmente mientras se ponían en marcha las obras complementarias de diversos planes ${ }^{10}$ que fueron incluidos en el más importante de ellos - y el que logró el mayor financiamiento-: el Plan de Terminación de Yacyretá (PTY), firmado en el año 2003. Recién en marzo de 2011 se llegó a la cota definitiva de $83 \mathrm{msnm}$, permitiendo la producción de energía en la mayor capacidad instalada de la presa. Para ello, se inundaron grandes áreas (Figuras 2 y 3 ) de las ciudades de Posadas (estimadas en 2.568,83 hectáreas, que representa un 8,2\% del

10 El PISMA (Plan de Infraestructura Social y Medio Ambiental), el PMMA (Plan de Manejo de Medio Ambiente) y el PARR (Plan de Acción para el Reasentamiento y la Rehabilitación) fueron planes que originarían importantes modificaciones en la trama urbana, observables tempranamente sobre todo en la ciudad de Posadas. 
distrito urbano) y de Encarnación ${ }^{11}$ y más de dieciséis mil familias relocalizadas, que equivalen a unas ochenta mil personas aproximadamente (Entidad Binacional Yacyretá, 2009, p. 3).

De los objetivos del PTY, enumerados en la introducción, aquellos que más importan para este trabajo, por su incidencia en los espacios de vida urbanos de las paseras paraguayas, son los últimos dos: el tendiente a reponer las obras de infraestructura afectadas por la inundación (rutas, puentes, puertos, vías férreas, etc.) y el que busca "recomponer la trama urbana de Encarnación y Posadas". Este último objetivo se llevó a cabo con planes posteriores, como por ejemplo el Proyecto Ejecutivo del Tratamiento Costero (PTC), ganado por licitación por una consultora con sede en Buenos Aires para la planificación, dirección y construcción de las obras complementarias y defensa costera para la ciudad de Posadas dentro del PTY (Millán, 2010). Estas obras de intervención urbana incluyen: inundación (incluidos los puertos de pasajeros de ambas ciudades) y planificación urbana de las áreas costeras de Posadas y Encarnación —-mediante convenios con la Corporación Puerto Madero (Carísimo, 2011) - , construcción de avenidas costaneras en Posadas y Encarnación, construcción de nuevas zonas comerciales en Encarnación, etc.

11 Los terrenos urbanos inundados abracaron los barrios de Barrio Obrero, San José, Estación, San Blas, Pacú Cuá, Bernardino Caballero, Carlos Bolik, La Paz, Villa Cándida, Potiy, Carlos Antonio López, Defensores del Chaco, entre otros. 
Posadas y Encarnación antes y después del embalse, una vez alcanzada la cota $83 \mathrm{msnm}$

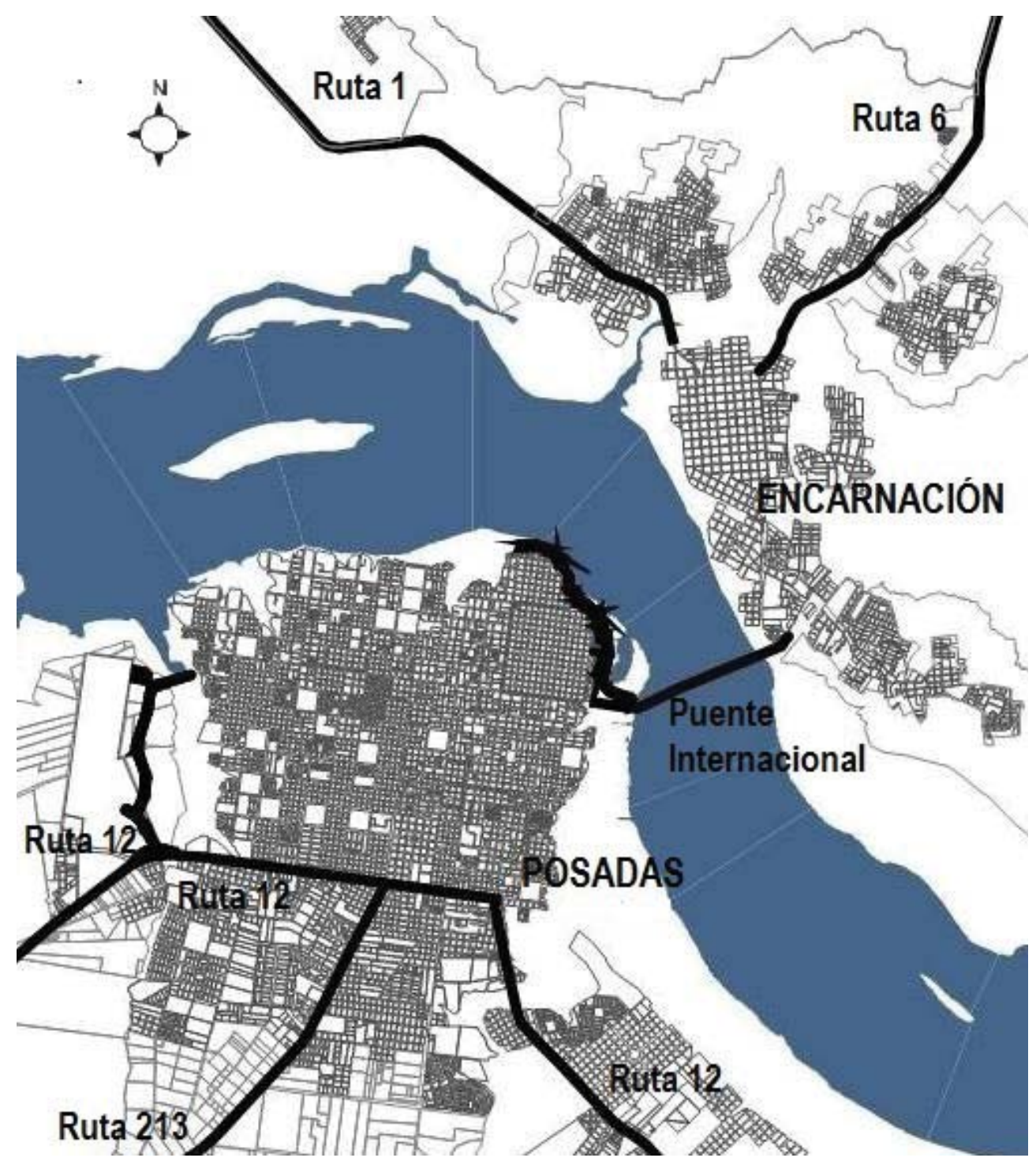




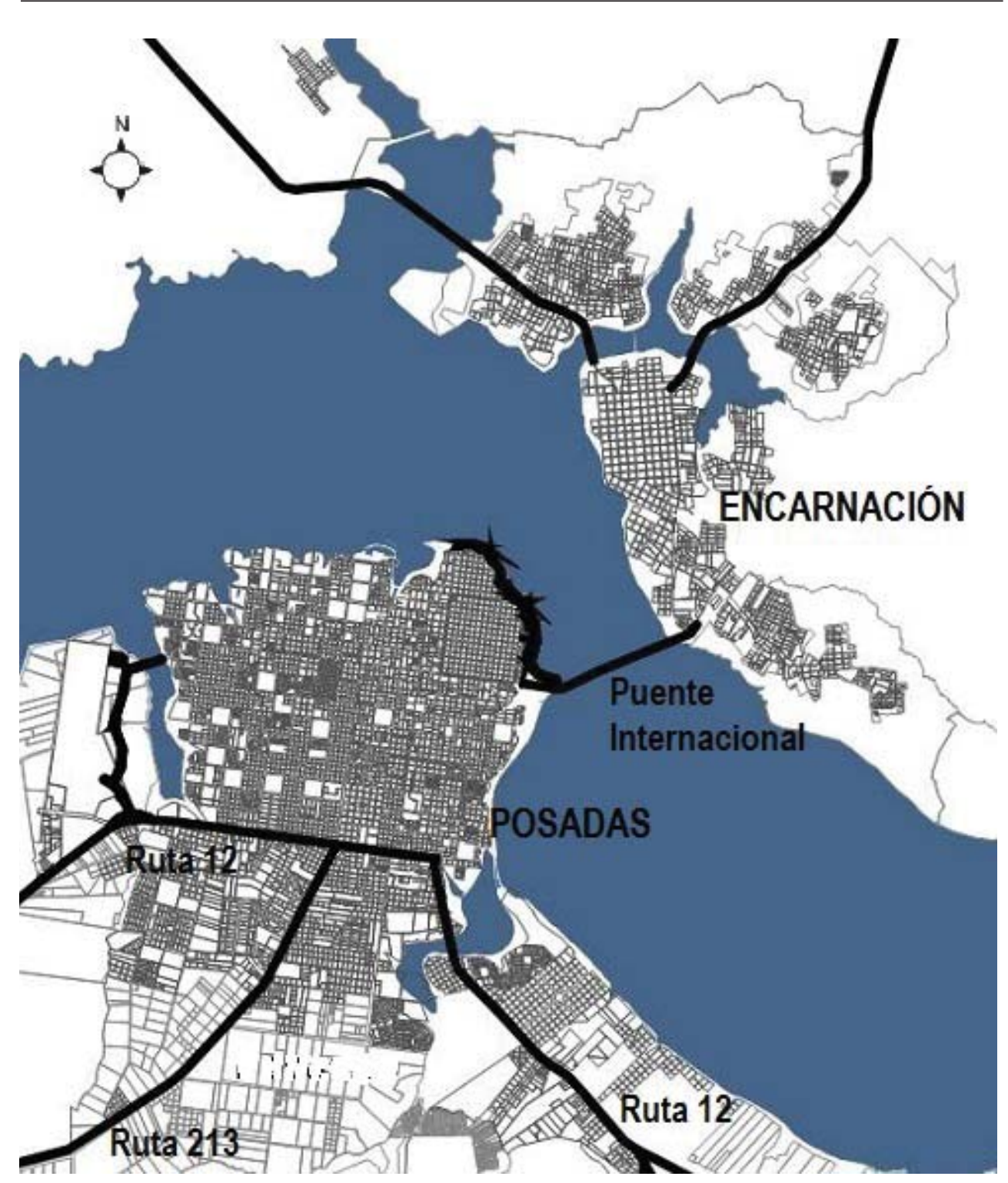

Fuente: Empresa Binacional Yacyretá, 2010. 
En pocos años, el paisaje urbano de Posadas fue transformado: los antiguos habitantes del área costera - tradicionalmente un área de pescadores, lavanderas, portuarios- fueron relocalizados y en lugar de sus viviendas humildes se construyó la avenida costanera (Figuras 4 y 5) como un espacio de esparcimiento público, y se habilitó la construcción de restaurantes, hoteles, edificios y casas de lujo, transformando el antiguo barrio popular portuario en un espacio público "moderno" y de consumo destinado a la clase media alta de Posadas (Barreto, 2004). Dentro de este cambio, el puerto de Posadas fue inundado e inutilizado a mediados del año 2009, y las vías de comunicación con el "Mercado Modelo La Placita" dejaron de ser transitadas por el constante ir y venir de las paseras desde el puerto al mercado. El Mercado Modelo, centro de compraventa vinculado a Encarnación por dos vías de comunicación, el puente internacional y el puerto, quedó así semiaislado y enfrentando un futuro incierto, ya que el PTY aspiraba a su completa relocalización, según las entrevistas realizadas a arquitectos de la Subsecretaría de Ordenamiento Territorial de la Provincia de Misiones (Arq. Borio, 2009) y de la Empresa Binacional Yacyretá (Arq. Cabral y Arq. Cabassi, 2010).

Figura 4: Mismo sitio: paisaje urbano de la costa posadeña aledaña a la cabecera argentina del Puente Internacional, año 2007, y Figura 5: mismo paisaje urbano luego de las reformas del PTY: Unidad Territorial Urbana Costanera Centro-Posadas (Proyecto 4), año 2010.

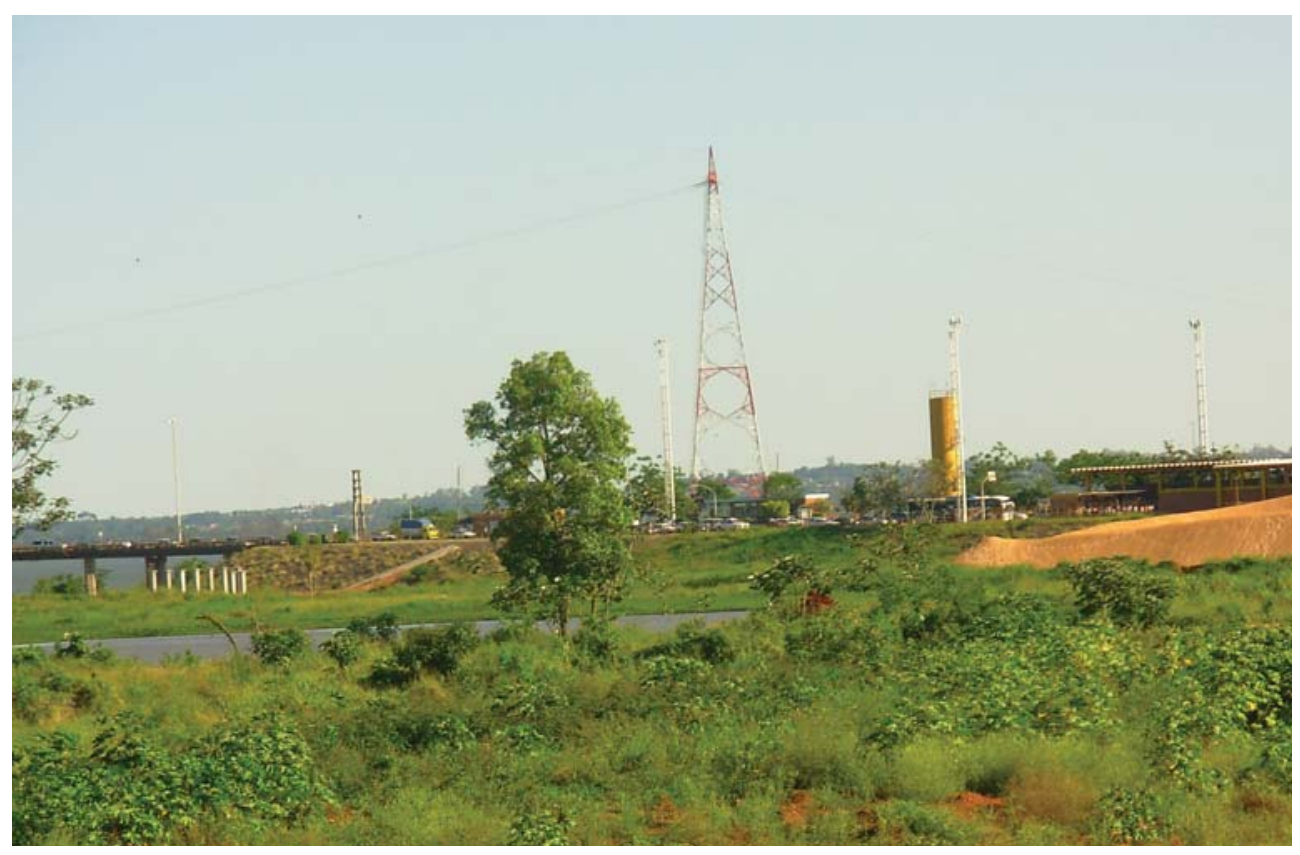




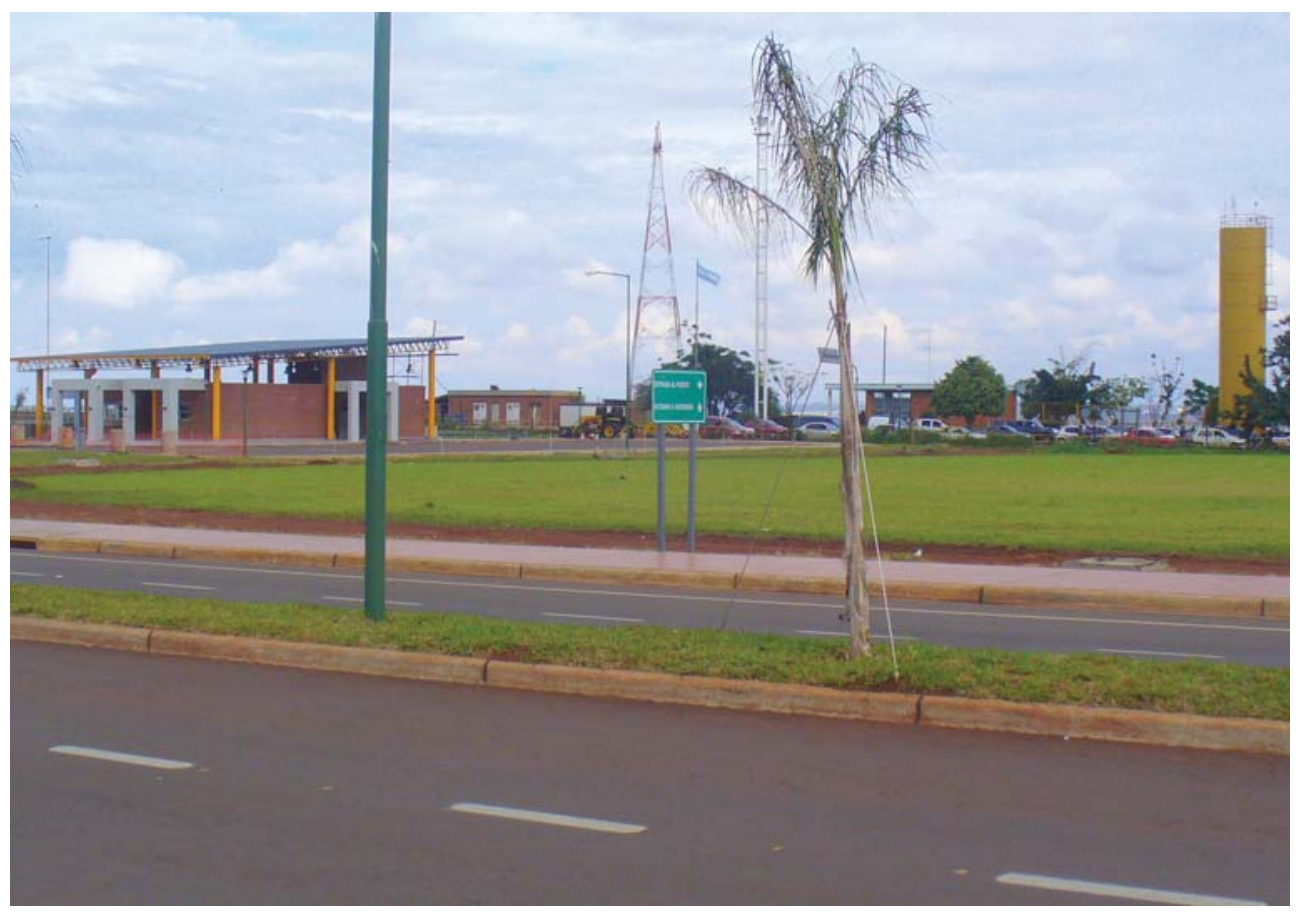

Fuente: fotografías de la autora.

Por otra parte, en Encarnación la inundación ha hecho desaparecer en su totalidad el casco histórico de la ciudad y, junto con él, su puerto y el barrio comercial de la "zona baja" (Figura 6), donde residía el 30\% de la población urbana del lugar. Con un margen recuperado por la defensa costera se construyó una avenida costanera de doce kilómetros que cuenta con espacios de recreación e incluso un balneario, hoteles y restaurantes. La actividad comercial que se desarrollaba en la zona baja de la ciudad fue trasladada casi en su totalidad a un predio construido exclusivamente para tal fin a unos doscientos metros de la cabecera paraguaya del Puente Internacional, y el recorrido del ómnibus internacional ha cambiado para llevar a los turistas directamente a esa zona de compras (Figura 7). 
Figura 6: Inundación en la "zona baja" antes de su total demolición. Figura 7: Nuevo barrio comercial, Encarnación, 2010.
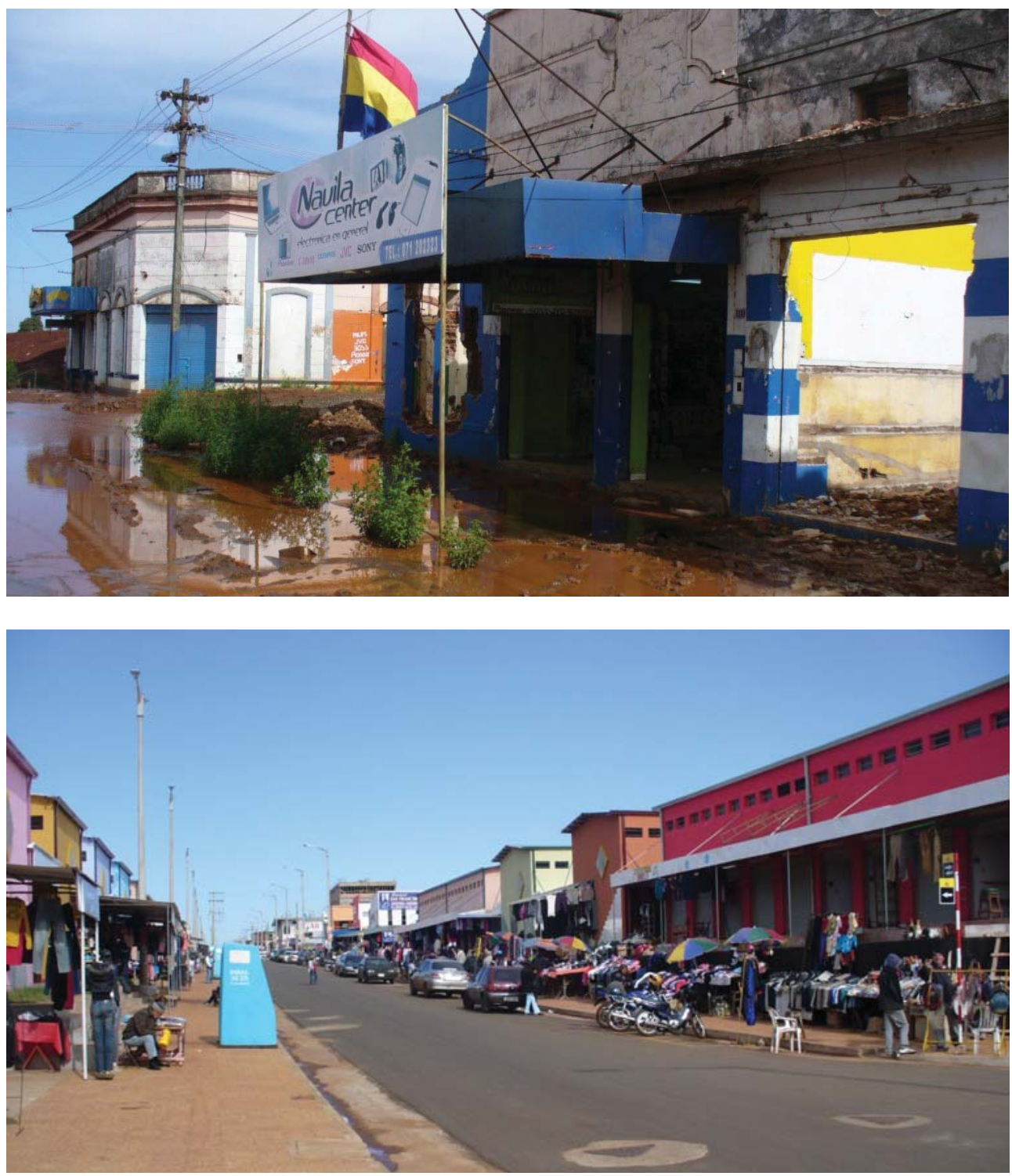

Fuente: fotografías de la autora. 
La materialidad del paisaje urbano había cambiado rápidamente: los objetos que lo conformaban habían desaparecido bajo las aguas y perdido su función. La justificación de las obras a ambos lados del río Paraná se sostuvo a partir de un hecho inexorable e insoslayable: el aumento del nivel de las aguas hasta la cota de $83 \mathrm{msnm}$, hecho que ayudó a "naturalizar" las intervenciones urbanas realizadas. Sin embargo, los cambios realizados en Posadas respondieron, además de a la lógica del "progreso" y "desarrollo"12 económico consecuente de la central hidroeléctrica y del consiguiente nuevo lugar ocupado por la ciudad a nivel regional, a un objetivo de segregación social de los sectores pobres de la ciudad. De esta manera, la opción por "dar la cara al río" o el interés de proyectar el centro de Posadas sobre el eje costero ya no respondió a las actividades productivas como las que estaban presentes en el planeamiento urbano del Plan Posadas de 1972 (Jaume, 1991), sino en "aumentar el valor del suelo, construir nuevos edificios en altura y habilitar el uso del suelo para las actividades comerciales y de servicio” (Millán, 2010, p. 256) sin tener en cuenta la estructura socioespacial anterior a las reformas. El PTY no solo cambió el paisaje urbano sino que, al mismo tiempo, dejó a miles de personas sin sus medios de subsistencia. Por esta razón, los conflictos sociales desencadenados a partir de relocalizaciones no alcanzaron únicamente a las familias sujetas a desalojos, también a una serie de actividades productivas ligadas al río, como pescadores, lavanderas, etc. Y el turno les llegaría también a las paseras paraguayas.

\section{Territorios en disputa: nuevos circuitos fronterizos de las paseras paraguayas y los desafíos frente al cambio}

Como observamos en el primer apartado, mediante las entrevistas a las paseras paraguayas y los ejercicios de observación definimos la dinámica de sus circuitos fronterizos entre los años 2009 y 2010. En reglas generales, dependiendo de las mercaderías que comercializan y de la red de relaciones de cada pasera, ellas manejan una variedad de combinaciones de circuitos que se definen según dos formas de realizar el "cruce": por medio del ómnibus internacional por el puente o en lancha por los puertos de Posadas y Encarnación. Hasta

12 Sobre el concepto de "progreso" y su implicancia en la República Argentina, ver Oscar Oszlak, La formación del Estado argentino. Orden, progreso y organización nacional, Buenos Aires: Planeta, 1997; y Maristella Svampa, El dilema argentino: civilización o barbarie. De Sarmiento al revisionismo peronista, Buenos Aires: El cielo por asalto, 1994. Encontramos un resumen del análisis conceptual del término "desarrollo" en Gustavo Berton, Apreciaciones conceptuales del término "desarrollo" Revista Huellas, 13, 192-203, 2009; y Adriana Carísimo, Transnacionalidad en situación de frontera: trayectorias de las políticas desarrollistas en Paraguay, ponencia presentada en IX RAM Culturas, Encontros, Desigualdades, Curitiba, 10 al 13 de julio, 2011. 
el mes de octubre del año 2009, esa era la primera y más importante decisión del día, y de su resultado dependía el trabajo de subsistencia para estas mujeres. Luego, en Posadas, las estrategias y los espacios frecuentados variaban según las mercaderías transportadas y los circuitos específicos de comercialización, es decir, según se pudiera o no armar puestos en la calle, según las relaciones sociales con vecinos, según se vendiera casa por casa o se trabajase simplemente de intermediaria con los puestos del Mercado Modelo.

En el mes de julio del año 2010, la actividad de los distintos tipos de paseras cambió. La territorialización de la EBY era evidente: el puerto de pasajeros de Posadas y el de Encarnación estaban bajo el agua y de la zona comercial baja de Encarnación ya no quedaba rastro alguno. Las paseras "verduleras" ya no podían ir a Posadas diariamente: al no existir más el puerto estaban obligadas a cruzar por el Puente Internacional, donde los funcionarios del SENASA imposibilitaban el ingreso de productos perecederos de sus huertas y chacras. Algunas de ellas, como María Paula, se aventuraban aun dos o tres días por semana con sus verduras. Con el fin de evidenciar la transformación en la representación del espacio urbano en los sujetos entrevistados reproducimos las palabras de María Paula: entre nuestra primera entrevista en abril de 2009 y la segunda en julio de 2010, su percepción del trabajo en la frontera había cambiado y, según ella, nuestra investigación también: "Lo que usted hace ya es historia, ahora no hay más puerto, no hay más trabajo, es parte del pasado". El cambio en el paisaje urbano material, del puerto al puente, provocaba una nueva fuente de incertidumbre para las paseras, el "cruce" se hacía cada vez más difícil:

-Ahora que no está la lancha es difícil para trabajar ahí, por el puente no pasamos, algunas veces si tenés suerte pasamos bien, sino mandamos todo de vuelta y no trabajamos (Lina, pasera verdulera, 19/07/10).

-Y ahora con el puente, qué le vamos a hacer, a veces pasamos bien a veces no pasamos. Hoy estaba feo y esta semana va a estar feo todo el tiempo. Porque el señor se fue de vacaciones, el señor que es bueno y nos deja pasar. Esta semana va a ser bravo con nosotras (Augusta, pasera verdulera, 19/07/10).

-Antes (cruzaba) con la lancha, ahora en colectivo por la creciente, porque no hay mas lancha $(. .$.$) iPrefiero por la lancha, toda la vida! Porque el control era más simple, y por$ la comodidad también... era más lindo y más rápido (Tamara, pasera intermediaria, 06/08/10). 
Pero, además, se sumó la pérdida de referencia espacial de todas las paseras con la desaparición de la zona baja de Encarnación, donde compraban, armaban sus bolsos, almorzaban, tenían sus clientes y sus contactos. Augusta dice que "en la zona baja no hay nada para hacer, es un desastre". Melisa, que tenía un puesto como "mesitera"13 en la zona baja, no fue censada en el año 2007 porque por problemas de salud estaba en su casa y no pudo trasladarse a la nueva zona comercial. Al quedarse desempleada decidió trabajar como pasera:

Yo tenía un puesto en la zona baja y no me dieron un puesto en la zona nueva porque tenía que estar en un censo del 2007, y yo no estaba porque en esos días estaba haciendo un tratamiento acá en Argentina, y ellos se fueron. (...) Yo si consigo que me den mi puesto... dejo este trabajo (de pasera). Porque este trabajo no es bueno, cada día para comer, hacer este riesgo... (Melisa, pasera intermediaria, 21/07/10).

La relación entre las funciones de las paseras, sus representaciones (la construcción del espacio urbano subjetivo) y la estructura del nuevo paisaje urbano se complejizó cuando, además de lo anteriormente mencionado, las paseras sufrieron una relocalización de sus viviendas por parte de la Empresa Binacional Yacyretá. Es el caso de Laureana que sigue trabajando en su puesto de verduras en Posadas, "pasa" de a poco sus mercaderías y aún sobrevive porque tiene un puesto fijo, pero la han relocalizado por las obras de la zona baja y no le han asignado una casa para ella y sus doce hijos, por lo que vive con la familia de su hermana en condiciones de hacinamiento.

Las paseras entrevistadas decían comprender para qué servían los grandes trabajos de infraestructura, pero compartían la idea de que tanto las obras de caminos, los nuevos barrios de consumo, así como el Mercosur, "son para los grandes, para los que tienen plata y son ricos, no son para nosotras, las hormiguitas" (Augusta, 19/07/10). Los "que tienen plata", los "grandes", son los beneficiarios de estas reformas que se están dando en el espacio fronterizo, mientras las paseras se sienten cada vez más excluidas:

-Es que no existe el Mercosur. Acá no existe, no para el chiquitaje. Ellos se la agarran por la mercadería poca, por las poquitas cosas que vos traés. Lo grande pasa todo, eso se sabe de toda la vida (Mariel, pasera vendedora, 26/07/10).

-En los primeros tiempos había más trabajo. Ahora pasan los más grandes y nosotras las hormiguitas no podemos pasar más nada (Jacinta, pasera, 27/04/09).

13 La actividad de los "mesiteros" consiste en armar mesas de venta en las veredas céntricas urbanas. 
-Sí, eso sí que cambió mucho (por el Mercosur y las obras del PTY). Antes cruzabas por la lanchita sin problemas, pero ahora hay problemas. (...) No nos dejan pasar. $\mathrm{Y}$ van y vienen camiones con muchas cosas, pero son los que trabajan en grande... Pero los que no tienen plata, como yo, ¿cómo hacemos para traer muchas cosas? (...) A los empresarios los ayudó, pero a la gente pobre, yo por ejemplo que soy apenas vendedora de frutitas... (Florencia, pasera verdulera, 10/08/10).

-Las cosas están peor que antes, digo yo. Eso (por las obras, el puente, el Mercosur) fundió nuestro país... a los pobres los fundió. Y nosotros somos pobres. Fundió a nosotros (Pasera anónima $N^{\circ} 1$, verdulera, 19/07/10).

La sensación que prima entre las paseras es la del "recorte" de sus viejos circuitos: pueden continuar haciendo su trabajo, pero ya no por la zona baja de Encarnación, ya no por la lancha, ya no sin los estrictos controles del puente, ya no por la costanera hasta llegar al "Mercado Modelo La Placita". Los recorridos de su circulación fronteriza han sido truncados, "limpiando" el espacio urbano (material) de su presencia y, por esta razón, sus "territorialidades en los intersticios" están en proceso de reformulación: las plazas donde se reunían quedaron bajo el agua, las esquinas donde armaban sus puestos ya no son transitados y los lugares donde compraban quedaron muy lejos de sus domicilios. Estos cambios son vivenciados con un sentimiento de "ajenidad" y desconcierto. Algunas paseras, sin saber leer ni escribir, declaran que les resulta muy difícil solicitar información a la sede de la Empresa Binacional Yacyretá por la situación de su expediente, por lo cual dicen desconocer cuándo comenzaría el nuevo servicio de lanchas, si les darán las casas prometidas, si podrán acabar con el hacinamiento y la precariedad. Mientras otros sectores de la sociedad encarnacena y posadeña se organizan para reclamar por sus derechos (Figuras 8 y 9), las paseras continúan su circulación intentando sortear los nuevos escollos, rogando pasar desapercibidas. La resignación con la cual afrontan diariamente los controles fronterizos y la posibilidad de perder sus mercaderías se traslada a los recortes en su circulación "laboral" cotidiana. 
Figura 8: "El progreso es muy lindo, pero no a costa de nuestras vidas y sufrimiento", manifestación de los relocalizados del barrio El Brete en la Plaza San Martí de Posadas, año 2007. Figura 9: "Encarnación S.O.S. nos ahoga la EBY", pintada anónima en zona baja de Encarnación, año 2010.

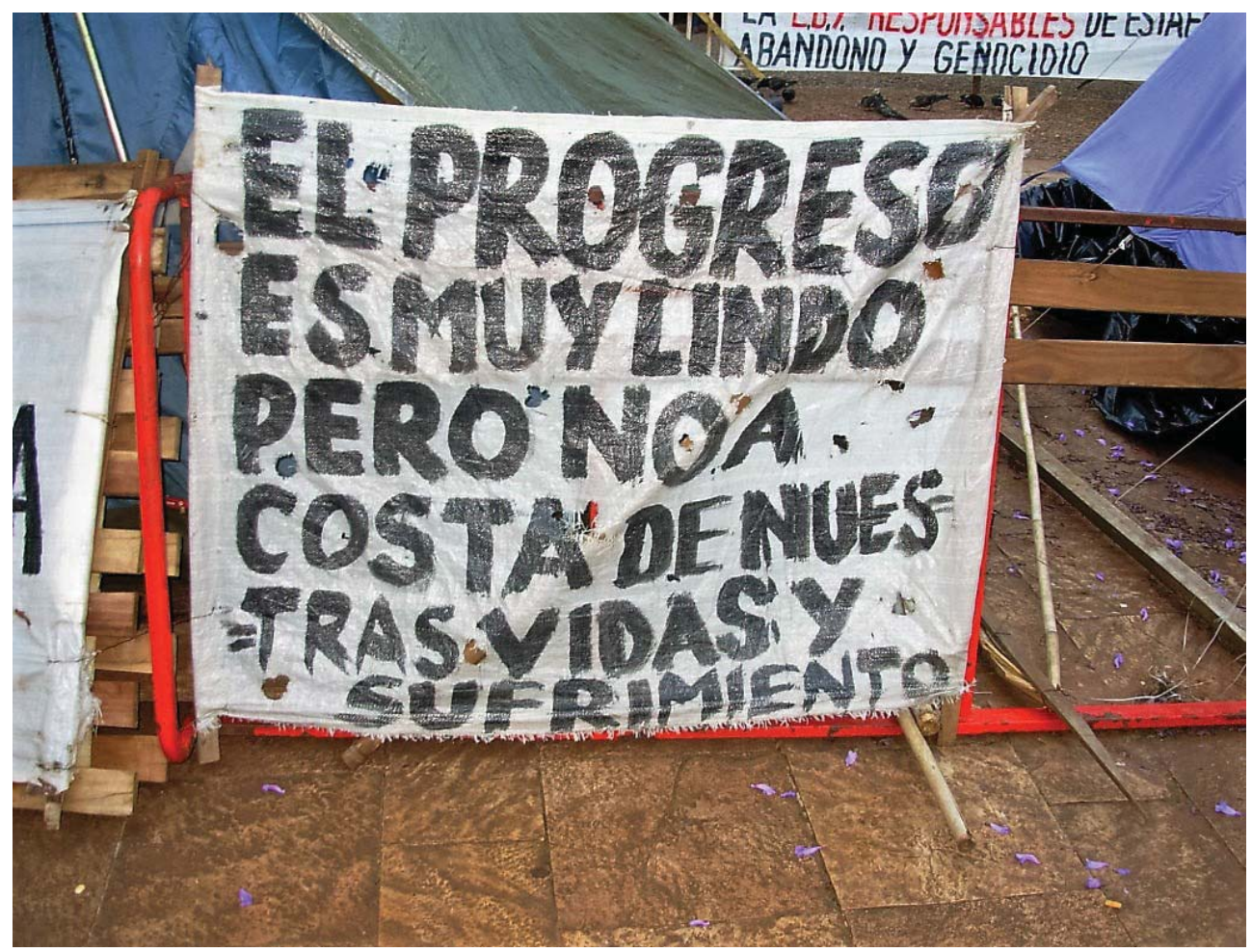




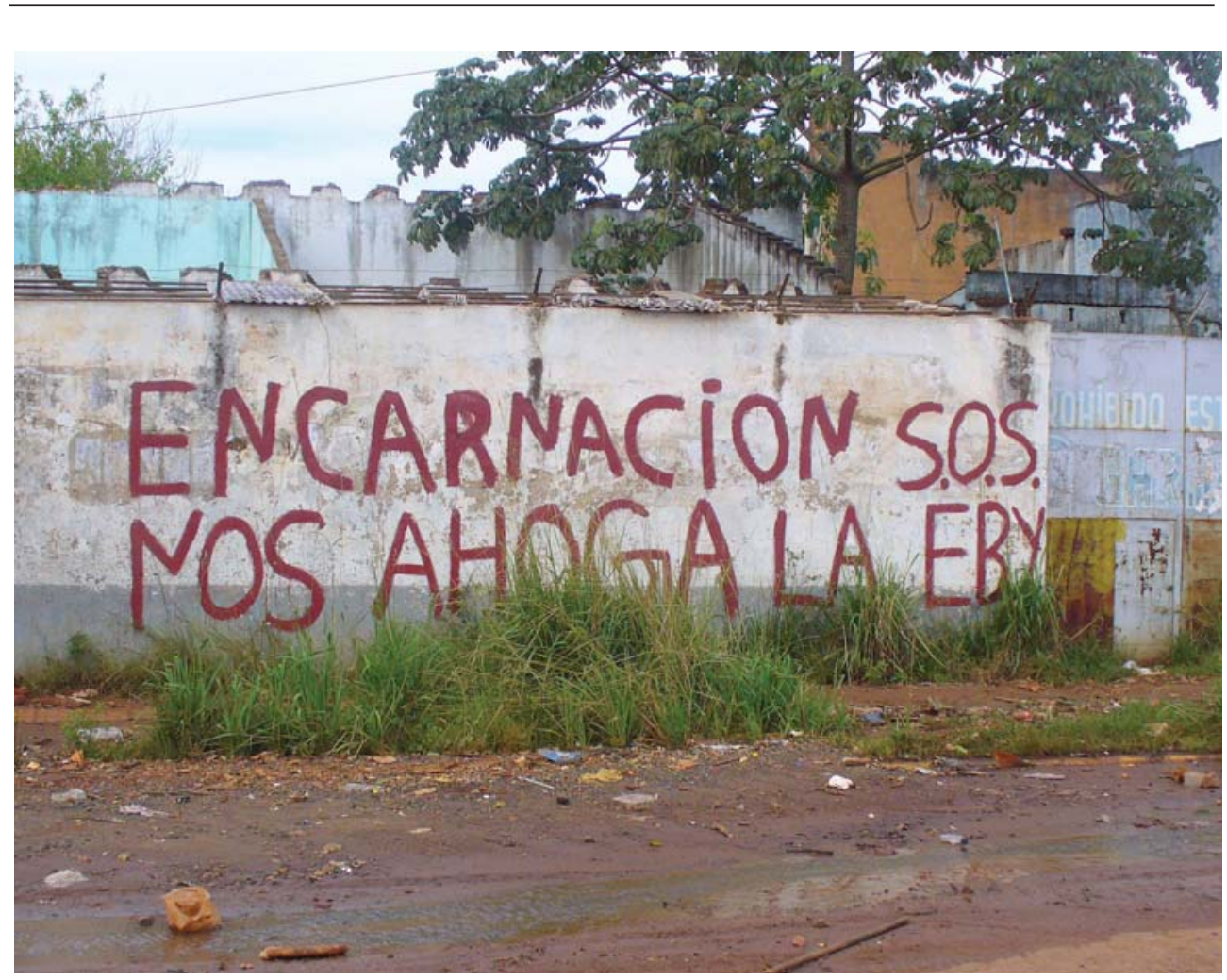

Fuente: fotografías de la autora.

Cabe remarcar que en julio del 2015, años después de finalizado nuestro trabajo de campo, la EBY construyó un muro de cinco metros de altura y 1.500 metros de largo en la cabecera argentina del puente internacional. Este muro se levantó en tan solo un mes de trabajo y está destinado a endurecer los controles en la circulación de bienes y mercancías, dado que separa la Zona Primaria Aduanera ${ }^{14}$ del resto de la ciudad de Posadas, obligando a aquellos que cruzan la frontera a recorrer varios kilómetros antes de llegar a la ciudad y entorpeciendo - hasta el punto de hacerlo impracticable - el "comercio hormiga" de las paseras paraguayas.

14 Según el Código Aduanero, la Zona Primaria Aduanera es aquella parte del territorio aduanero habilitada para la ejecución de operaciones aduaneras o afectada al control de las mismas, en la que rigen normas espaciales para la circulación de personas y el movimiento y disposición de la mercadería. 


\section{Conclusiones}

El espacio fronterizo en Posadas-Encarnación está atravesado, como vimos, por prácticas sociales que desafían la discontinuidad espacial que implica el límite internacional, siendo una de estas la del "comercio hormiga" de la pasera paraguaya. Desde la construcción e inauguración del puente internacional en 1990, la función coercitiva de las ordenanzas municipales y nacionales, los requisitos para cruzar la frontera y trabajar en cada zona de Posadas y asimismo las prohibiciones al ingreso de ciertas mercancías (medidas sanitarias o bromatológicas) han influido en el desarrollo de la capacidad de las paseras para sortear estos y otros obstáculos en su trabajo cotidiano, sumando así recursos a su accionar de resistencia y resignación. La discontinuidad geográfica de la frontera fue así resistida por sus prácticas de circulación a partir de diferentes estrategias: con pequeñas infracciones diarias a las normas argentinas, cruzando mercadería prohibida en escasa cantidad, caminando por fuera de los circuitos permitidos, vendiendo "casa por casa" en el centro mismo de Posadas o "tomando" esquinas céntricas para armar precariamente un puesto de venta. Sus saberes, el manejo de información sobre la "temperatura del puente o del puerto", sus técnicas de cruce de los bultos, funcionaron como un contrapeso al desequilibrio relacional con las normativas y con el control del Estado argentino.

Esa relación, este juego precario de poder asimétrico sobre el territorio (la territorialización estatal versus la territorialización en los intersticios del "comercio hormiga"), volvió a sacudirse con el inicio de las obras del PTY. Si bien este plan fue aprobado en 2003, recién en el año 2009 las obras que traerían el "desarrollo" a Posadas y a Encarnación fueron homogeneizando el paisaje urbano fronterizo: las montañas de tierra colorada removida por las obras, las casas derrumbadas, las grandes máquinas hormigoneras se hicieron visibles en ambas orillas del Paraná y comenzaron a formar parte de las representaciones de las paseras paraguayas sobre su espacio de vida. Además de los controles cotidianos en "el paso", se sumó para ellas una nueva preocupación y un nuevo problema que solucionar: el recorte espacial de su vida cotidiana, donde está incluido el trabajo entre las ciudades de Posadas y Encarnación. Las quejas de las paseras entrevistadas nos demostraron que en la representación del paisaje urbano entre Posadas-Encarnación como lugar de trabajo aparece, con las obras del PTY, un aumento del maltrato por parte de las autoridades en la cabecera del puente internacional y el recorte de su espacio de trabajo en la ciudad de Posadas. La limitación de trabajar, circular, descansar en ciertas zonas de la ciudad y no en otras, es percibida por ellas como injusto, desde el punto de vista socioeconómico. A partir de sus palabras observamos una "escala" nativa (Frederic y Soprano, 2009) a tener en cuenta: la separación entre los "grandes" (los ricos, el Mercosur, los funcionarios de la 
EBY, los que realizan las grandes obras) y "nosotras las hormiguitas" (mujeres pobres que van con su peso a cuestas).

Por esta razón, estimamos que este espacio fronterizo presenta también dos dimensiones de un mismo dato. Como afirma Carísimo (2011), el análisis de la escala supranacional e internacional de las obras de infraestructura energética puede mostrar las matrices de desarrollo regional. Pero estas obras tienen una dimensión definida en términos espaciotemporales, en donde es posible problematizar la cotidianidad de esas matrices. En ese sentido, el espacio de vida de las paseras paraguayas ha sido atravesado de manera abrupta por las materializaciones de las matrices de desarrollo imperantes en el área, matrices de las cuales, además, se sienten inevitablemente excluidas. El desarrollo para unos pocos (los que tienen dinero, en este caso) implica para este actor fronterizo un recorte espacial y una posterior marginalización laboral. Esta representación espacial de las obras va acompañada de un sentimiento claro de exclusión, el cual manifiestan con resignación pero no sin tensión, ya que se suma a la excusión "tradicional" que sienten en los controles fronterizos por ser paraguayas, paseras, mujeres, etc. Su percepción nos muestra un paisaje urbano donde prima la estructura material y se borran las huellas de las prácticas sociales y de las subjetividades. La suma de sentimientos negativos con respecto a su posibilidad de subsistencia establece dudas sobre la capacidad de "resiliance" frente a los últimos cambios socioespaciales de las paseras paraguayas. Mientras desde la escala internacional las obras del PTY están generando un tipo de desarrollo económico del espacio fronterizo, desde la escala micro-socio-espacial recorta, excluye y margina a varios actores sociales, entre ellos a las paseras paraguayas.

\section{Referencias bibliográficas}

Amilhat-Szary, A.-L. y Fourny, M.-C. (dir) (2006). Apres les frontieres, avec la frontiere. Nouvelles dynamiques transfrontalieres en Europe. París: Laube.

Arriaga Rodríguez, J.C. (2012). El concepto frontera en la geografía humana. Perspectiva Geográfica, 17, 71-96.

Barreto, M. A. (2004). Transformaciones de la vida urbana de Posadas y Resistencia a fines de los años '90. Un estudio sobre la dimensión simbólico-ideológica del espacio urbano político. Tesis de Doctorado en Antropología inédita. Universidad Nacional de Misiones, Posadas. 
Benedetti, A. (2011). Lugares de frontera y movilidades comerciales en el sur sudamericano. Una aproximación multiescalar. En Costa, E. A., Costa, G. V. L.; Oliveira, M.A.M. (comps.), Fronteiras em foco (pp. 33-55). Campo Grande: Editora da UFMS.

Berton, G. (2009). Apreciaciones conceptuales del término “desarrollo". Revista Huellas, 13, 192-203.

Carísimo, A. (julio, 2011). Transnacionalidad en situación de frontera: trayectorias de las políticas desarrollistas en Paraguay. Ponencia presentada en IX RAM Culturas, Encontros, Desigualdades. Curitiba, Brasil.

Cortés, G. y Faret, L. (2009). Les circulations transnationales. Lire les turbulences migratoires contemporaines. París : Armand Colin (Collection U, Sciences Humaines et Sociales).

Corvalán, G. y Elías, R. (1999). Mujer y empleo en áreas de frontera: impacto del Mercosur. Asunción: Secretaría de la Mujer, Presidencia de la República.

De Bourgoing, A. (1984). Viajes en el Paraguay y Misiones. Recuerdos de una expedición a los Yerbales de Concepción, Cerro Corá y Sierras de Amambay, Etc. Paraná: Litografía y Enc. La Velocidad.

Di Meo, G. (1998). Géographie Social et territoires. París: Nathan.

Díez de Velasco, M. (1975). Instituciones de Derecho Internacional Público. Tomo I. Madrid: Tecnos.

Entidad Binacional Yacyretá (2009). Plan de Acción para el Reasentamiento y Rehabilitación (EBY-PARR). Informe: "Desarrollo social en ambas márgenes". Posadas: Entidad Binacional Yacyretá.

Entidad Binacional Yacyretá (2005). Actas Nº67 del 27 de enero de 2005, Comité Ejecutivo. Disponible en: http://www.yacyreta.org.ar/docum/2006/tratadodeyacyreta.pdf.

Entidad Binacional Yacyretá (1981). Resolución Nº 103 de 1981, Consejo de Administración. Disponible en: http://www.yacyreta.org.ar/docum/2006/tratadodeyacyreta.pdf.

Entidad Binacional Yacyretá. Resolución N 1530, Consejo de Administración. Disponible en: http://www.yacyreta.org.ar/docum/2006/tratadodeyacyreta.pdf. 
Entidad Binacional Yacyretá. Resolución № 5752, Comité Ejecutivo. Disponible en: http:// www.yacyreta.org.ar/docum/2006/tratadodeyacyreta.pdf.

Ferrari, M. (2014). As noções de fronteira em geografia. Revista Perspectiva Geográfica, 9, (10), 1-25.

Foucher, M. (1991). Fronts et Frontières. Un tour du monde géopolitique. París: Fayard.

Frederic, S. y Soprano, G. (comps.) (2009). Política y variaciones de escala en el análisis de la Argentina. Buenos Aires: UNGS-Prometeo Libros.

George, P. (1974). Dictionnaire de la Géographie. París: PUF.

Haesbaert, R. (2004). El mito de la desterritorialización. Del fin de los territorios a las multiterritorialidades. México D.F.: Siglo XXI

Jaume, F. (1991). Conformación histórica de una sociedad regional. Urbanización, Economía Informal y Marginalidad en la Provincia de Misiones. Posadas: Documento PROBUR.

Kralich, S., Benedetti, A. y Salizzi, E. (2012). Aglomeraciones transfronterizas y movilidad. Una aproximación desde casos sudamericanos. Boletim Gaúcho de Geografia, 38, (1), 111-136. Disponible en: http://seer.ufrgs.br/index.php/bgg/article/view/37319/24101.

Linares, M. D. (2010), Prácticas comerciales fronterizas de las mujeres paraguayas "paseras" en la ciudad de Posadas, Argentina. Contribuciones Científicas GAEA, 22, 327-338.

Linares, M. D. (2013). La frontera entre la permeabilidad y el "piquete". Las transformaciones socio-territoriales en el paso Posadas (Argentina)-Encarnación (Paraguay) durante la década del noventa. Revista Transporte y Territorio, 9, 39-64.

Linares, M. D. (2015). Lugares de frontera en la circulación entre Posadas (Misiones, Argentina) y Encarnación (Itapúa, Paraguay). Estudios Socioterritoriales. Revista de Geografía, 17, 49-75.

Millán, M. (2010). La figuración del frente costero para la ciudad de Posadas. Polis, Revista de la Universidad Bolivariana, 9, (27), 243-267.

Oszlak, O. (1997). La formación del Estado argentino. Orden, progreso y organización nacional. Buenos Aires: Planeta. 
Pastor Ridruejo, J. A. (1992). Curso de derecho internacional público y organizaciones internacionales. Madrid: Tecnos.

Peyret, A. (1881). Cartas sobre Misiones. Buenos Aires: Imprenta de la Tribuna Nacional.

Raffestin, C. (1974). Espace, temps et frontière. Cahiers de Géographie de Québec 18, 23-34.

Santos, M. (1996). Metamorfosis del espacio habitado. Barcelona: Oikos.

Schiavoni, L. (1993). Pesadas cargas, frágiles pasos. Transacciones comerciales en un mercado de frontera. Posadas: Centro Paraguayo de Estudios Sociológicos y Editorial Universitaria.

Simoe, N. (2003). Proyecto Yacyretá: un largo y complejo proceso de reasentamiento. Informe presentado en Forum Técnico: reassentamento involuntario. San Salvador de Bahía: Banco Mundial.

Souto, P. (2011). El concepto de paisaje. Significados y usos en la geografía contemporánea. En: P. Souto (coord). Territorio, Lugar, Paisaje. Prácticas y conceptos básicos en geografía (pp. 129-183). Buenos Aires: Colección Libros de Cátedra, Facultad de Filosofía y Letras, UBA.

Svampa, M. (1994). El dilema argentino: civilización o barbarie. De Sarmiento al revisionismo peronista. Buenos Aires: El cielo por asalto. 